\title{
A PROPÓSITO DEL REALISMO DE MARIO BENEDETTI
}

\author{
POR \\ ELSA DEHENNIN \\ Universidad Libre de Bruselas
}

El caso de Mario Benedetti me intrigó bastante en la época del boom. A este novelista, muy leído en el Uruguay, uno de los más vendidos y estimados por la crítica, lo situaba al margen de lo que podría llamarse la novela nueva o la novela moderna _en el mismo sentido que Carlos Fuentes daba a estos términos en su ensayo, La nueva novela hispanoamericana (México: Cuadernos de J. Mortiz, 1969). No veía muy clara su posición en la movida del boom.

La nueva novela estudiada por Fuentes - que no tiene nada que ver con el nouveau roman francés, llamado por él "la novela del realismo neocapitalista" aparece en una perspectiva más bien universal como "mito, lenguaje yestructura" (20). Es también la novela de "la modernidad enajenada" (26). El novelista mejicano insiste en estos rasgos comunes para destacar más las similitudes que las diferencias entre la novela hispanoamericana, por una parte, y la europea o norteamericana, por otra.

Como si además quisiera evitar toda dicotomía en la caracterización de la nueva novela hispanoamericana, Fuentes destaca "la síntesis crítica de la sociedad y la imaginación" que ésta elabora - asociando dos palabras cargadas de connotaciones a menudo opuestas. Tal "hecho central" lo encuentra también "constitutivo" de la prosa borgiana; por ejemplo: "esa síntesis crítica, más que el simple paso de la novela rural a la novela urbana, es lo que distingue ... las obras de los escritores más significativos de una etapa de tránsito de la tipicidad a la personalidad y de las disyuntivas épicas a la complejidad del aislamiento frente a la comunidad" (27). Y Fuentes cita en primer lugar a los uruguayos Juan Carlos Onetti, Carlos Martínez Moreno y Mario Benedetti. Sobre todo las obras de Onetti "son las piedras de fundación de nuestra modernidad enajenada y el más fiel espejo de nuestros hombres", "Ios intelectuales-objeto y las mujeressujeto" de Moreno y "los oficinistas" de Benedetti; pero hay muchos personajes más, argentinos, chilenos, mejicanos, y no todos hombres de la ciudad.

Aprovecha pues, curiosamente, el rasgo común de "síntesis crítica" para reunir a Borges con antípodas y pasar de una síntesis crítica que es "fantástica" a otra "realista" muy específica en un novelista como Benedetti. 
Hay que constatar al mismo tiempo que Fuentes no cita a Benedetti cuando analiza en el apartado "un nuevo lenguaje" (30). Un elemento que me parece constitutivo de toda modernidad literaria, no sóloen la novela hispanoamericana sino en cualquier novela del siglo XX, es la "nueva fundación del lenguaje" que observa en "el torrente verbal indiscriminado" de Lezama Lima o Cortázar, en el humor, tanto en la parodia de Manuel Puig como en el "calambur gigantesco" de Cabrera Infante; también en el "travestismo" de Severo Sarduy, por ejemplo.

Nuestra literatura es verdaderamente revolucionaria en cuanto le niega al orden establecido el léxico que éste quisiera y le opone el lenguaje de la alarma, la renovación, el desorden y el humor. El lenguaje, en suma, de la ambigüedad: de la pluralidad de significados, de la constelación de alusiones: de la apertura (32).

Se basa, sin duda, en el entonces famoso libro de Umberto Eco sobre la "obra abierta", como se basará también en Paul Ricoeur para valorar lo que me parece ser el rasgo decisivo de una modernidad literaria universal. Ésta se ha desarrollado por cierto espectacularmente en el siglo XX pero remonta al Barroco, si nos atenemos a la época moderna - tal como la entienden los historiadores-la que empieza en 1492.

La "modernidad enajenada" no es sólo un producto de la "civilización moderna" (29) tan tecnológica que inquieta mucho a Fuentes. Más allá de un cuestionamiento existencial trae consigo una subversión o perversión del lenguaje, magníficamente manejada por Joyce, para citar a uno de los máximos representantes de la modernidad literaria de este siglo. Fuentes habla de la "palabra enemiga" (85), que la crítica contemporánea ha interpretado desde Tzvetan Todorov (1967) como una palabra opaca y que es una palabra fundamentalmente antimimética. En esta perspectiva el combate es el mismo para todos los escritores de lengua española: Fuentes constata, a propósito de la obra de Juan Goytisolo, que "todos nosotros, españoles e hispanoamericanos, hemos de reconocer la quebradiza ruina de nuestra propia imagen y de nuestra propia cultura. No es otro el mensaje de esta literatura de exilados que escriben algunos autores de nuestra lengua común: todos somos contemporáneos porque todos somos excéntricos" (84).

He insistido a guisa de introducción en este texto significativo para situar a Benedetti en la "nueva novela hispanoamericana": está al margen de la modernidad que va en busca, lo queramos o no, de la "inmensa minoría" y dentro de un realismo más tradicional, grato a la mayoría.

Sé que los términos subrayados son difíciles de circunscribir; sobre todo la palabra "modernidad" sigue suscitando en nuestraépoca de "postmodernidad" debates apasionados. ${ }^{1}$ La entiendo, independientemente de la enajenación que

${ }^{1}$ Modernidad y postmodernidad, compilación José Picó (Madrid: Alianza, 1988). 
puede traer consigo, como el resultado de la larga y progresiva lucha, siempre renovadora y progresista, lanzada contra la mímesis aristotélica durante la época moderna, lucha iniciada por un tal Góngora, poeta maldito, verdadero héroe de "la palabra enemiga", y que se acaba, según los teóricos de la postmodernidad, en este fin de milenio.

No hace falta que la analice más detalladamente aquí ya que el realismo - y es otro término conflictivo cuyo campo semántico intentaré delimitar-va a preocuparnos. Sólo hacía falta plantear la relación dialéctica que hay entre mimetismo y antimimetismo. Benedetti se sitúa en la corriente (mainstream, dicen los ingleses) del realismo. No cuestiona la mímesis.

Los críticos que no dejan de lado a Benedetti (silenciado, por ejemplo, por Luis Harss en Los nuestros, o sólo mencionado por Andrés Amorós en Introducción a la novela hispanoamericana actual) insisten en rasgos que se pueden considerar como constitutivos del realismo mimético.

Emir Rodríguez Monegal (1974) ${ }^{2}$ analiza sus ficciones como las "de un testigo implicado" (209), o sea como las de un montevideano:

lo que este autor parece querer decir (y decirnos) es que así somos los montevideanos: mediocres, superficiales, resentidos, frustrados. $Y$ lo dice de modo que no tengamos más remedio que reconocernos ... Curiosamente, este informe negativo no está dicho con odio sino con amor, ya que Benedetti no se alza por encima de sus criaturas para juzgarlas sino que comparte con ellas penas y glorias (216).

Sus relatos son en efecto subjetivos y cognoscitivos.

Para José Donoso (1972) , ${ }^{3}$ que ubica a Benedetti "en el grueso del boom", Montevideanos pertenece a "una serie de libros que aspiran a servir de atajos para llegar lo más pronto posible a una conciencia de lo que, en los diversos países, es lo nacional" (46). La actitud que observa también en libros como Lima la horrible, Adán Buenosayres oLa región más transparente, entre muchos otros, es la de una "angustiada curiosidad adolescente por contemplarse desnudo en el espejo para conocerse de una vez por todas" (47).

En cuanto a D. L. Shaw (1985), ${ }^{4}$ insiste en la actitud ideológica de Benedetti y en su compromiso político, desarrollados fuera de los textos literarios en numerosos ensayos. Lo asocia con un escritor como David Viñas con quien comparte una "ideología abiertamente revolucionaria" (16).

Frente a ellos Shaw sitúa otro grupo "capitaneado en cierto modo por Borges, para quienes la literatura funciona como algo autónomo de su contexto inmediato económico, político y social" (14). Topamos así con la binaridad

\footnotetext{
${ }^{2}$ Emir Rodríguez Monegal, Narradores de esta América (Buenos Aires: Alfa, 1974), tomo 1, 209-225.

${ }^{3}$ José Donoso, Historia personal del boom (Barcelona: Anagrama, 1972).

${ }^{4}$ Donald L. Shaw, Nueva narrativa hispanoamericana (Madrid: Cátedra, 1985).
} 
hispanoamericana que Fuentes quiso pero no pudo evitar, la de cosmopolitismo/ americanismo, y que se puede enfocar como una oposición literaria mucho más amplia, universal pues, de mímesis necesariamente referencial versus antimímesis autorreferencial $o$ arreferencial.

Nadie puede negar que la mímesis aristotélica es la norma literaria de siempre. Nadie debería extrañarse de que el realismo mimético, referencial pues, representa la tradición mayoritaria tanto de la literatura hispánica, española e hispanoamericana, como de cualquiera otra literatura.

Dentro del marco aristotélico bien conocido, en el cual "poesía" e "historia" se oponen como el relato de lo general versus el relato de lo particular, el relato de hechos que podrian ocurrir versus el de hechos que han ocurrido (Poética 1451b), la poesía, llamada literatura siglos después, "de un carácter más filosófico y más elevado/profundo" que la historia, es la imitación verosímil de una realidad que existe o no existe. "Los acontecimientos son posibles según la verosimilitud o la necesidad," dice Aristóteles en el mismo famoso apartado. El criterio de lo posible, que no excluye lo irracional ni lo absurdo, va condicionado por el de lo verosímil. "Hay que preferir lo imposible que es verosímil al posible que es increíble" (1460a), lo que sabe perfectamente Cervantes y ... García Márquez.

La imitación verosimil ha sido interpretada a lo largo de la historia -me refiero, por ejemplo, a la Philosophia antigua poética de López Pinciano (1596) que tuvo tanta influencia en el Siglo de Oro- como una imitación de acontecimientos que sea conforme a la razón y/o la religión (la moral). Ambas, razón y moral, han idoevolucionando como valores, muylenta o muy rápidamente, y con ellas la norma de verosimilitud, que no dejó de ser sin embargo la norma de lo sensato, de la decencia, de la belleza y del famoso buen gusto, grato a académicos y burgueses, sobre todo en Francia, un canon más o menos oficial, convencional, instituido por cada época.

Esta norma Ramón Menéndez Pidal, filólogo ejemplar del siglo XX, la interpretaba como "la transustanciación poética de la realidad". 5 Dio lugar a una mímesis artística secular, clásica, equilibrada, referencial, necesariamente realista, un realismo passe-partout, que nunca se llamó realismo. La palabra se impone en el siglo XIX (desde 1833 en Francia) para designar la corriente literaria antirromántica bien conocida cuya meta era - cito a Jakobson (1921) "reproducir la realidad lo más fielmente posible" y que aspira pues "a un máximo de verosimilitud" (99).

5 "Caracteres primordiales de la literatura española" (1949), en España y su historia (Madrid: Minotauro, 1957), t. II, 641.

B "Du réalisme artistique", en Tzvetan Todorov, Theorie de la littérature (Paris: Seuil, 1975), 98-113. 
Según R. Wellek (1963), el realismo como period concept intenta dar "una representación objetiva de la realidad social contemporánea" (240-41). ${ }^{7}$ Notamos que las determinaciones van delimitando y especificando más y más el concepto de mímesis. Sabemos además que el realismo decimonónico representa a menudo el mundo degradado de las clases medias y bajas, que conviene a la novela, antigénero con respecto a los grandes géneros que son la épica o la tragedia.

A partir de entonces hay que distinguir:

- la mímesis aristotélica convencional, la norma de siempre (sentido 1)

-y el realismo, una mímesis marcada, parcial (sentido 2) a menudo polémica, revolucionaria en ciertos momentos (también los futuristas reinvindican el realismo) y retrógrada, hasta arcaica, en otros (para los Telquelistas, por ejemplo, a los cuales se acerco S. Sarduy).

Hoy día hay que agregar más sentidos a los numerosos ya destacados por Jakobson quien, al distinguir sentidos A y sentidos B (99), supo anticiparse a la crítica de la recepción. Mientras la mímesis se mantiene au-dessus de la mêlée hasta en nuestra época postmoderna, el realismo postdecimonónico opone conservadores y progresistas, pero de tal manera que los progresistas de ayer o de allí son los conservadores de hoy o de aquí, y que los progresistas del contenido pueden ser los conservadores de la expresión. Gran renovador por la imaginación, García Márquez opta por técnicas tradicionales.

Huelga decir que utilizo la palabra "realismo" como un término descriptivo y no como un término de valor.

¿Cómo entender pues hoy el realismo (sentido 3) que no se puede confundir ni con la mímesis secular ni con el realismo decimonónico?

De todos los estudios que leí sobre el realismo el que más me ayudó para comprenderloy destacar sus rasgos constitutivos es un estudio poco conocido del semiólogo italiano Piero Raffa, Vanguardismo y realismo (1967), dedicado al teatro de Pirandello, Jarry, Mayakovski y Brecht, autores "realistas" que se caracterizan por "un elemento fantástico" y por la "estilización".

Leí este libro en una época en que en Francia la crítica y la (neo)vanguardia ( $T e l$ Quel) cuestionaban la noción de verosimilitud y rechazaban cualquier forma de mímesis.

Gérard Genette (1968) consideraba lo verosímil como "un significado sin significante" y R. Barthes (1968), al examinar l'effet de réel notabaque "la carence

\footnotetext{
${ }^{7}$ Concept of Realism in Literary Scholarship", en Concepts of Criticism (New Haven: Yale University Press, 1963), 240-41. En la página 250 debe confesar sin embargo: "I hesitate to inclu de 'objectivity', in the sense of absence of the author, as an indispensable criterion of realism". El método quiere ser objetivo pero apenas lo consigue. De hecho, el "autor" suele estar muy presente.

\& Communications (1968), 11. Ver en particular los artículos de Gérard Genette, "Vraisemblance et motivation" 521 y de Roland Barthes, "L'Effet de Réel", 84-89.
} 
même du signifié au profit du seul référent devient le signifiant même du réalisme". La obra realista no era más que un gran vacio artístico.

Tal no es el punto de vista de Raffa, para quien realismo y vanguardismo son compatibles. La noción de un realismo expresivo no mimético la debo a él. No la desarrollaré aquí.

Piero Raffa parte de una caracterización general del arte totalmente compatible con la mímesis: el arte es para él "la expresión de ideas -actitudes" (297). Observa que "el realismo es una categoría del significado, no del signo" (285) -lo que podemos interpretar en una perspectiva más lingüística que semiótica como una categoría del significado antes que del significante. El significante por creador que sea va siempre si no subordinado al significado, cualificado por él.

El realismo es un tipo de lenguaje artístico cuya caracteristica principal consiste en comunicar significados cognoscitivos con la función subordinada de cualificar la actitud expresada (301).

Aunque el arte no es jamás conocimiento, el realismo artístico nos propone significados cognoscitivos, que Raffa entiende como "constituídos por juicios relativos a lo que existe" (292) y - lo añado aristotélicamente-a lo que puede existir, a los universos posibles de un García Márquez, por ejemplo, que suele insistir en el realismo de su obra. ${ }^{9}$ El lenguaje de la obra realista es necesariamente referencial.

Aludo a una frase de Paul Ricoeur que supo diferenciar tan agudamente "référence suspendue" y "référence déployée" en su estudio sobre la metáfora (1975) y ve el lenguaje atravesado por dos movimientos:

l'un qui sépare le signe de la chose et le rapporte à d'autres signes dans la clôtu re d'un systeme lingüistique, l'autre qui applique le signe à la réalité, le rapporte au monde et ne cesse de compenser le mouvement de la différence par celui de la référence. ${ }^{10}$

Vemos aquí toda la diferencia que hay entre mímesis y antimímesis, entre el realismo que privilegia l'effet de réel, y la modernidad que intenta borrarlo.

Pero el realismo no se caracteriza solamente por significados cognoscitivos, o sea referenciales y denotativos: éstos cualifican una idea-actitud que es para Raffa "el eje en torno al cual gira toda estrategia del lenguaje" (298): "el

\footnotetext{
${ }^{9}$ Severo Sarduy, Escrito sobre un cuerpo (Buenos Aires: Sudamericana, 1969), incluye en el "ejercicio de realismo", rechazado por su "lastre verista", "su peor variante: el realismo mágico" (63).

${ }^{10}$ Cito la frase según Jean Bessière, Le Récit fantastique (París: Larousse, 1974), 244. Ver también "Le plaidoyer contre la réference" del mismo Paul Ricoeur, in La Métaphore vive (París: Seuil, 1975), 279 y ss.
} 
significado principal del lenguaje artístico" (322). Esta actitud en una obra realista es la "pasión humanista por la realidad". Aunque se trata de otro término de difícil demarcación semántica, el humanismo supone "el atenerse a los hechos, es decir el tener en cuenta lo que existe y nos condiciona, nos agrade o no" (323). Los hechos degradados, diría Goldmann, ${ }^{11}$ no suelen coincidir con los valores, ni los conocimientos con los ideales: "la pasión humanista por la realidad es el empeño siempre renovado (históricamente) de descubrir en qué punto se halla esta relación entre hechos y valores" (324), entre degradación y valores auténticos, entre rabia e ilusión. No hay que confundir esta actitud humanista con una actitud ideológica. ${ }^{22}$

Resumiendolo que tomo prestadoa Raffa, diría que el realismo se caracteriza:

-por significados cognoscitivos, referenciales

$\rightarrow$ supeditados a una actitud humanista que determina la estrategia del lenguaje.

Agrego:

-una estrategia de las más variables, que puede optar por el movimiento de la referencia (de tipo semántico) o el de la diferencia (de tipo semítico), por un lenguaje transparente o por un lenguaje opaco, ${ }^{13}$ fundamentalmente poético, estilizador y por ende desrealizador (pero no deshumanizador).

Hay un registro muy variado de realismos (sentido $3 \mathrm{a}, \mathrm{b}$, c, etc.) que podríamos representar por un eje que va de un polo - a un polo +:

-de un realismo directamente mimético, con una expresividad mínima (en España se hablaba en la postguerra de un realismo de urgencia que fracaso artísticamente) - de "significado sin significante"-

-a un realismo expresivo, como el de Rayuela, por ejemplo, donde hay significados con significantes, sin que la obra, "mito, lenguaje y estructura, como lo quiere Fuentes, citado supra, llegue a ser mero significante tal como lo quiere Barthes. ${ }^{14}$

${ }^{11}$ Lucien Goldmann, "Introduction à une Sociologie du roman" en Pour une Sociologie du roman (Paris: Gallimard, 1964), 35-36.

${ }_{12}$ Ver Piero Raffa, Vanguardismo y realismo (Barcelona: Ediciones de cultura popular, 1967), 329. Mientras que el significado principal (actitud) aparece cualificado por el conocimiento en el realismo, en el arte ideológico aparece cualificado por una ideología. Piensa Raffa que es justo "considerar el arte comprometido como una variedad ideológica del realismo, como un realismo 'comprometido" (333).

${ }^{13}$ Tzvetan Todorov, Litterature et Signification (Paris: Seuil, 1967), 102. El discurso opaco lo define como "un discours sans référence" ... "Un langage qui ne renvoie à aucune réalité, qui se satisfait à lui-même".

${ }_{14}$ Roland Barthes, L'Aventure sémiologique (París: Seuil, 1985), 13: "l'instance du Texte n'est pas la signification, mais le Signifiant". 
He podido comprobar que esta estrategia del lenguaje que comunica significados inmediatamente o mediatamente cognoscitivos, según que la referencia sea "desplegada" o "suspendida", se relaciona con una actitud que pasa del humanismo señalado por Raffa a lo que podria llamarse un abhumanismo, un humanismo de signo negativo, rebelde, propio de la "modernidad enajenada", que se rebela más contra los valores que contra los hechos. Este abhumanismo, que un crítico francés observó en Audiberti, ${ }^{15}$ no ve otra solución para las angustias del hombre enajenado, ángel caído que ha perdido definitivamente el paraíso, que la destrucción del mundo, una destrucción creadora llevada a cabo por una "palabra enemiga" muy querida, mencionada antes.

A la luz de estas consideraciones se entenderá mejor el realismo mimético -ortodoxo- de Benedetti, que se atiene:

-a unos significados cognoscitivos predilectos-montevideanos admirablemente "recepcionados" por Rodriguez Monegal (1974, t. 2, 217),

-un humanismo que denuncia la enajenación de los oficinistas, de la clase media en general, y del "Uruguay fundado por los padres" en particular, y un lenguaje transparente, referencial, informativo, descriptivo, explícito, monosémico, parafraseable, diría $\mathrm{Ph}$. Hamon, ${ }^{16}$ "une écriture de la socialite" ${ }^{17}$

En cuanto al discurso (la enunciación enunciada del narrador y de los personajes, modalidad importante del lenguaje novelesco) hay que notar una preferencia por las formas puras o del modo personal, en primera persona, de tipo autobiográfico y monológico, o del modo apersonal en tercera persona con los tiempos del pasado, con la presencia de la instancia implícitamente subjetiva que he llamado en otra ocasión el narrador comunicador (NC) ${ }^{18}$ un $\mathrm{NC}$ que interviene no para "destructurar" el discurso, sino al contrario, para homogeneizarlo.

No hay experimentación ni juego discursivo. Impera la seriedad que no excluye la risa negra, una ironía crítica.

Benedetti, que está convencido de que "es demasiado absorbente nuestra realidad como para que no influya en nuestros escritores", que ha denunciado la fallutería nacional, observa que "la palabra no existe, como quieren algunos ideólogos de la derecha, para ser protagonista de la nueva narrativa

\footnotetext{
${ }^{15}$ A. Deslandes, "Un abhumanisme très humain". La nouvelle NRF, 13 (1965): 1037-40.

16 Philippe Hamon, "Un discours contraint". Poétique 16 (1973), 411-45.

${ }^{17}$ C. Duchet, "Une écriture de la socialite". Poétique, ibid., 446.

${ }^{18}$ Gérard Genette, Figures III (Paris: Seuil, 1972), 188 ve la presencia del "narrador" como "source, garant et organisateur du récit, comme analyste et commentateur, comme styliste ... et particulièrement ... comme producteur de 'métaphores'.
} 
latinoamericana. No, el protagonista sigue y seguirá siendo el hombre; la palabra, su instrumento" (1978). ${ }^{19}$

Quisiera ver más concretamente cómo funciona el realismo en un cuento de Benedetti, "Sábado de Gloria" de 1950, publicado en Montevideanos (1959). Es uno de los cuentos preferidos por el propio autor (con "Familia Iriarte" y "Los pocillos" en el mismo libro). Aunque Rodríguez Monegal (1974) estima que no es uno de los mejores cuentos, lo juzga "revelador". Comparto este juicio que querría justificar ateniéndome al sistema discursivo del cuento.

Como no puedo resumir aquí el método narratológico que suelo utilizar, ${ }^{20}$ citaré a Cortázar (1984), que nos dejó pocas consideraciones teóricas, pero que citó excepcionalmente a Michel Foucault en un apartado sobre el "estilo". ${ }^{21}$ Esta cita me conviene perfectamente.

Hay que distinguir en todo relato, según nuestros dos autores interesados en Julio Verne, "la fábula, lo que se cuenta, de la ficción, que es 'el régimen del relato', la situación del narrador con respecto a lo narrado" (t. 1, 145). La relación entre ambos "sólo puede establecerse en el interior del acto mismo de la palabra; lo que se cuenta debe indicar por sí mismo quién habla, a qué distancia, desde qué perspectiva y según qué modo de discurso". Y se añade algo de lo que estoy muy convencida: "la obra no se define tanto por los elementos de la fábula o su ordenación como por los modos de la ficción, indicados tangencialmente por el enunciado mismo de la fábula" (ibid., 146). La tripartición retórica - inventio, dispositio, elocutio-nose ha perdido yla elocutio la considero aquí como enunciación.

No voy a insistir mucho en la "fábula" que suelo llamar diégesis, y que corresponde al mundo narrado. No creo que haga falta destacar los significados cognoscitivos del cuento ni su actitud humanista, muy evidentes, nada ambiguos: tendría que describirlos parafraseando lo que nos dice Benedetti o repetir de algún modo lo que la crítica ha dicho ya. ${ }^{22}$ Me atendré a la "ficción" en su relación "tangencial" con la "fábula".

El cuento se presenta como el relato en primera persona hecho por un oficinista, un típico "montevideano" de clase media, tan bien descrito por Rodríguez Monegal (1974), ${ }^{23}$ un pauvre type anodino, un yo, mero pronombre sin

\footnotetext{
${ }^{19}$ Mario Benedetti, "El escritor y la crítica en el contexto del subdesarrollo", Casa de las Américas, 107 (1978), 11.

${ }^{20}$ "En pro de un análisis estructural del cuento", en Teorías semiológicas aplicadas a textos españoles (Universidad de Groningen: 1979), 35-41 cuando sólo intuía una teoría que puede resumir más coherentemente en "Los discursos del relato", Actas del VIII Congreso Internacional de Hispanistas (Berlín: Vervuert, 1989), de inminente publicación.

${ }^{21}$ La vuelta al día en ochenta mundos (Madrid: Siglo XX, 1984), tomo 1, 145-47.

${ }^{22}$ Recopilación de textos sobre Mario Benedetti (La Habana: Casa de las Américas, 1976). (Compilación y prólogo de A. Fornet).

${ }^{23}$ Ver Emir Rodríguez Monegal (1974), op. cit., 217, que ha insistido también en los problemas edípicos de muchos personajes.
} 
nombre propio, que cuenta cómo su mujer, Gloria, enferma de repente un sábado después de la siesta y muere durante la noche. El título, "Sábado de Gloria", añade pues al sentido normal del sintagma, una ironía amarga y distanciadora. No hay ningún domingo de resurrección para Gloria.

El narrador respeta espontáneamente la ley de las tres unidades: la de acción - hay un solo acontecimiento de degradación progresiva e irreversiblela de lugar -aunque hay el "departamento de dos habitaciones" y el hospitaly la de tiempo - ni siquiera 24 horas - que plantea sin embargo un problema no en la "fábula" sino en la "ficción": ésta de modo personal intenta combinar el desarrollo cronológico ab initio de hechos pasados con el suspenso ligado a un presente anterior al desenlace fatal, o sea una visión perfectiva de una instancia que sabe lo que ha ocurrido con una visión imperfectiva de una instancia que no debe de saberlo, ya que se instala en el presente del acto de palabra para decirnos lo que está ocurriendo.

Hay dos presentes muy distintos en el cuento: el presente que es el de los comentarios genéricos, muy abundantes en toda la parte introductoria, $\mathrm{y}$ el presente deíctico, hic et nunc, no muy frecuente, en el cual coinciden el decir/ escribir y el actuar del narrador-personaje (homodiegético).

Sabemos que en cualquier relato personal alternan dos yo. L. Spitzer hablaba de erzählendes ich y de erzählte ich. La pragmática optó por otra terminología. Emplea metáforas como embragar y desembragar, derivadas de la categoría lingüística de los shifters. En un contexto teórico más amplio hablaría de un narrador narratorial ( $\mathrm{Nn}$ ) (yo + tiempos del presente, en el acto de palabra) y de un narrador diegeta (yo + tiempos del pasado, o sea de la "fábula"). Sea cual sea la terminología, tenemos aquí los dos modos básicos del narrador: el de los locutores explícitos, narrante o narrado, detrás de los cuales hay siempre una instancia implícita, llamada enunciador por Oswald Ducrot, ${ }^{24}$ y que llamo el narrador comunicador (NC); simplificando mucho diré que tiene que ver con el "implied author".

El título, por ejemplo, se debe al NC: es una marca verbal, lingüística, de la expresión, lo que llamo un síntoma del NC, la instancia más o menos subjetiva, presente o más bien ausente, cercana o lejana, que se percibe en filigrana detrás de los narradores explícitos, y que suele comunicarnos la actitud, una actitud humanista, que resumiría en este cuento a través de la figura de la última línea, "mi apática ternura hacia Dios" (24), donde ironía y oxímoron de determinante negativo se combinan para expresar la actitud del personaje y de su creador.

Veamos el incipit: suele ser importante; la matriz del relato, se ha dicho; determina el modo dominante de la "ficción". ${ }^{25}$

Desde antes de despertar, of caer la lluvia. Primero pensé que serian las seis y cuarto de la mañana y debía ir a la oficina ... Después creí que era domingo

${ }^{24}$ Oswald Ducrot et. al., Les mots du discours (Paris: Éditions de Minuit, 1980), 39-40.

${ }^{25}$ Mario Benedetti, Montevideanos (Buenos Aires: Alfa, 1975). 
y me podía quedar un rato bajo las frazadas. Eso - la certeza del feriado-me proporciona siempre un placer infantil (17).

Habla el Ndg que podría ser también una tercera persona; pasa rápidamente del pretérito y demás tiempos del pasado al presente, un presente no deíctico (embragante) sino génerico, durativo o repetitivo, que le permite al $\mathrm{Ndg}$ resumir detalladamente la "rutina semanal" de siempre, la suya más que la de Gloria, que los días sean laborales, festivos o "un sábado como éste" (18). En esta frase topamos después de una larga introducción que ocupa como una cuarta parte del texto, con el primer deíctico, un deíctico que ya no esperábamos y que significa que el $\mathrm{Nn}$ dice todas esas menudencias de la vida cotidiana el mismo sábado, día tan fatídico, como si no supiera nada del desenlace trágico.

Habrá cinco incursiones marcadas del $\mathrm{Nn}$, más unas pocas furtivas (de tipo "creo") con la repetición en cuatro de los cinco casos del mismo deíctico temporal (este, ese), casos todos concentrados en dos párrafos (3, 18-9 y 2, 23). Hay pues una marcada insistencia por parte del Nn en el hoy de "este sábado”, “de esta siesta". L'effet de réel de tales shifters es bien conocido: el lector comparte necesariamente este presente que crea la ilusión de un acontecimiento auténticamente vivido fuera del texto; tal actualización es un truco literario bien conocido y que se presenta también diegetizado, por ejemplo en "ahora no llovía" (21), ahora + imperfecto.

En un relato autobiográfico canónico-pensemos en Lazarillo de Tormesel $\mathrm{Nn}$ y el Ndg suelen alternar al principio y al final del relato: en estos momentos conviven en una situación narratorial o discursiva más o menos circunstanciada y posterior a los acontecimientos de la "fábula". Se genera la historia pasada a partir de esta situación de discurso que es la del acto mismo de la palabra hic et nunc. En el resto del relato se separan: prevalecen el Ndg y su mundo narrado mientras el $\mathrm{Nn}$ interviene intermitentemente con comentarios - siempre prescindibles pero que no deberían ser insignificantesde "fábula" o de "ficción", dictados o no por un NC más o menos perceptible, solidario o indiferente.

Tal no es el caso en este relato: mientras que el principio consta de un "sumario" indicial y el final de una "escena" más dramática, ambos se presentan como discursos, si no exclusivamente, ampliamente dominados por $\mathrm{Ndg}$. Cito las tres primeras irrupciones del $\mathrm{Nn}$ :

1. Los comentarios quedan para "un sábado como éste". (Porque en realidad era un sábado, el final de una siesta de sábado.) (18)

Se notará el paréntesis que opera un cambio de nivel discursivoinmediatamente después del shifter: agrega un comentario de otra instancia discursiva: del $\mathrm{Ndg}$, detrás del cual percibimos a un NC bastante distante, hasta ajeno; opta no sólo por un signo gráfico que señala la interrupción discursiva, sino también por la repetición del artículo indefinido un sábado, una siesta. Es como si el NC que 
confirma redundantemente con su autoridad omnisciente (en realidad) el decir del $\mathrm{Nn}$, pusiera en entredicho el efecto de la actualización producida por el deíctico éste. Borra la impresión de vivir el acontecimiento con su personaje narrante y a partir de él.

2. Sin embargo, "este sábado no hubiera sido de comentarios", porque anoche después del cine me excedí en el elogio de Margaret Sullavan ... (una actriz de la que Gloria tuvo celos y por la cual se durmieron reñidos) (19).

Se nota el subjuntivo imperfecto compuesto que expresa una irrealidad ya cumplida en el presente de "este sábado" percibida en su anterioridad desde un punto de vista posterior, a partir de un saber que el Nn explica pero que parece sobrepasarlo; vemos otra vez al NC que maneja la ficción desde fuera de la fábula.

3. Yo no tenía inconveniente en ser el primero (en hacer la paz), como en tantas otras veces, pero el sueño empez6 antes de que terminara el simulacro de odio y la paz fue postergada "para hoy, para el espacio blanco de esta siesta". (19)

Con esta frase llegamos al final de la parte introductoria que da el sumario iterativo de la vida cotidiana y frustrada de la pareja. Lainsistencia deíctica por parte del Nn sobre el nunc de la "fábula" se mantiene y coincide con una marca del NC: esta vez se trata de un juicio evaluativo - "el espacio blanco de esta siesta”. Llama la atención el adjetivo que anticipa metonímicamente la muerte de la esposa o/y, metafóricamente, el vacío que experimentará el protagonista. Es un determinante teleológico que el NC dicta al Nn, un NC que interfiere en el discurso del narrador protagonista sabiendo más que él. En estas condiciones no puede ser discursivamente solidario de él. Cortázar es un modelo de máxima solidaridad discursiva entre NC y el Nn (yo) o el Ndg (él). Lo consigue a menudo a través del discurso indirecto libre, muy expresivo en el relato de tercera persona. Aquí no hace falta. El discurso narratorial (Dn opuesto al discurso diegético, Ddg) se hace a veces oral (y es una trampa, claro,) pero el monólogo interior es rudimentario.

Quedan dos ocurrencias más hacia el final del relato cuando el $N$ dg describe "la amenaza de la muerte" y el sábado de "hoy" ha pasado.

4. Entonces entró una enfermera ... Entonces todo el presente era ella luchando por vivir ...

Entonces extraje la libreta y empecé a "escribir esto", para leérselo a ella cuando estuviéramos otra vez en casa, para leérmelo a mí cuando estuviéramos otra vez en casa (23).

Tenemos la sorpresa de topar con el máximo shifter escribir esto, pero es un pseudo-shifter: va integrado en un discurso diegético con dos pretéritos que expresan claramente un pasado perfectivo. El escribir es un hecho más de la 
"fábula", como "recé" o, "me dormi", no es la fuente genésica de la "ficción". Yo es una persona psicológica y referencial en un mundo cognoscitivo que (d)escribe terapéuticamente los hechos ocurridos; aunque es sólo pronombre, no es una persona formal en el acto de escribir, o en el acto de narrar, como es el caso en muchos relatos de hoy. Pienso en Ricardo Piglia.

Queda la última ocurrencia en el mismo contexto que confirma la recuperación total del Dn de la "ficción" por el Ddg de la "fábula", narrada retrospectivamente en una perspectiva dictada por un NC que no convive con su personaje.

5. De pronto me distraje ... [piensa en cosas más divertidas, "los partidos de hoy", "los asientos contables que escrituré esta mañana"] Pero me sentí profundamente ajeno "en ese sábado que habría sido el mio" (23).

Con esta frase en pretérito se desvanece el presente falazmente deíctico del $\mathrm{Nn}$ y vacila la visión imperfectiva, que daba a veces un tono de reportaje al texto; prevalecen hasta el final el pretérito y el imperfecto en un Ddg, no totalmente homogéneo sin embargo. Antes de la frase citada hay los dos shifters citados ("de hoy, esta mañana"). Después quedan dos presentes genéricos y unos shifters como "Yo no puedo creer verdaderamente en él" (Dios) (23) o "creo" como mero modalizador (24).

Toda la atención se concentra en el dramático desarrollo de la "fábula". El modo de "ficción" es incierto: pierde su efecto de actualización.

Notemos en el último ejemplo, sobre todo el demostrativo ése que se sitúa ya fuera de la zona del nunc, en un inactual difícil de delimitar y expresado también por un condicional compuesto, "habria sido". Podemos comprender que el Ndg, un yo enajenado y abrumado por el dolor, rechace tanto el real "había sido" como el irreal "hubiera sido" para atenerse a una forma conjetural bastante enigmática. Pero comprendemos también que el cambio de nivel discursivo se debe al NC que va imponiéndose más y más.

En la frase inmediatamente anterior a la citada en 5 y donde no hay shifters, había intervenido ya marcadamente el NC a través de dos presentes genéricos y un imperfecto con comentarios impersonales expresados en una enumeración de tres comparaciones paralelas que no se justifican ni en la "fábula" ni en la "ficción": (todo, y más que nada el "estar en casa", le parecía lejano al personaje) "tan lejano como la primera mujer cuando uno tiene once años, como el reumatismo cuando uno tiene veinte, como la muerte cuando sólo era ayer" (23).

Es inverosímil que estolo diga/escriba el personaje en la situación dramática en la que se encuentra: cuenta el Ndg pero habla el NC muy por encima de él. Lo vemos en el ejemplo 5 a través de "ese", un ex-shifter y "habría sido", que combina fuera de todo presente la anticipación del futuro con lo cumplido del pasado. El NC impone, en una perspectiva retrospectiva bien acabada, su actitud frente, no a esta muerte de la "fábula", sino a la muerte. 
La "ficción" renuncia a todo efectismo y sirve a la "fábula" y a su mensaje humanista ideado necesariamente por el NC. Los oximorones finales: "una oración a manoarmada, mi oración hiriente, un médicoodiosamente comprensivo, y la ya citada fórmula final", "mi apática ternura hacia Dios", todos síntomas del NC en el discurso del Ndg, expresan lo absurdo de la protesta humana frente a la muerte.

Si desde el punto de vista de la "fábula" perfectamente realista no hay mucho que decir, desde el punto de vista de la "ficción" observamos rupturas discursivas que en sí no son nada anómalas, pero cuya expresividad no me parece del todo lograda: no se justifican en una estrategia realista global y eficaz. En vez de aumentar la ilusión referencial de la presencia y de la autonomía del narrador personaje en un relato autobiográfico, las intervenciones del Nn muestran su dependencia del NC, el Padre que lo ha ideado todo, que optó por un realismo de "fábula" (con significados cognoscitivos y una actitud humanista) pero descuidó el realismo discursivo de la "ficción". 